\title{
Beyond Entertainment: Gastrodiplomacy Performance in Korean Drama and Reality Show
}

\author{
Vellycia ${ }^{1}$ \\ ${ }^{1}$ LSPR Communication and Business Institute, Jakarta, Indonesia
}

\begin{abstract}
As the world keeps advancing due to globalization, countries across the world were competing against each other to be more acknowledgeable. The use of nation branding appears to be better suited to solve that problem. The use of public diplomacy such as gastrodiplomacy is believed to be the perfect tool in achieving that goal. South Korea was one of the many countries to do so. The country does not solely rely on the concept of gastrodiplomacy alone, rather it combines diplomacy with the use of media and entertainment industry. This research aims to elaborate the use of Korean television programs as the medium for cultural
\end{abstract}

KEYWORDS gastrodiplomacy ; cultural representation; nation branding ; entertainment industry ; television programs

\section{INTRODUCTION}

As the world keep changing and developing due to globalization, the use of hard power such as economic threats and military forces were often reckoned to be causing violence (Gray, 2011), making countries across the globe begin to shift from the use of hard power to soft power. Soft power was reckoned to be better fitted, where it emphasizes the use of attraction and relationship between nations, using the country's political ideas, government's policies, and cultural aspects (Nye, 2004). Furthermore, the concept will be commonly used and introduced as public diplomacy.

Globalization created opportunities for countries to use media as tools for diplomacy, such as public diplomacy. This created a sense where public diplomacy was reckoned to be more effective and efficient, compared to conventional diplomacy. Furthermore, globalization open the possibility for the international public to partake in the process of diplomacy (Leonard, 2002). The use of cultural aspect of a country were deemed to be one of the key elements in conducting a public diplomacy campaign (Pamment, 2013). 
The popularity of using cultural aspect of a country as a tool for conducting a public diplomacy campaign keep increasing to date, where it was reckoned to be able to communicate and present something to the international public in a diffuse and attractive manner.

South Korea was one of the countries to do so. The country uses public diplomacy in many various ways. The Korean Waves or Hallyu was one of them, the term was used to explain the global phenomenon of Korean Pop Culture and entertainment industry across the globe. The craze did not just stop there, it expanded to the country's national cuisine, culture, and even language (Ministry of Culture Sports and Tourism and Korean Culture and Information Service, n.d.). The Korean Waves or Hallyu became an essential diplomatic and promotional tool of the country, resulting in the rapid growth and increase of the country's nation branding (Scharf, 2016). The craze had brought out significant impact on the popularity of Korean culture abroad, where many publics from across the globe noticeably fascinated by the culture.

Korean Wave or Hallyu had successfully attract and fascinate the international public towards the Korean culture, through the use of the country's entertainment industry, such as music and television programs. A study was conducted by Hee-Joo Han and JaeSub Lee (2008) stated that television programs did not only affect the tourism development, but also the overall image of the country. Furthermore, the study also mentioned that television programs could help wiped out any negative images of a country. With that being said, it created a sense where television programs could be more furtherly used as a tool for diplomacy.

The use of television programs, such as Korean drama and reality show were reckoned to be able to act as a medium for cultural representation, making it perfect for cultural diplomacy. The cultural aspect represented within, such as culinary culture could be used as tool to promote the country's nation branding. The use of culinary culture became more popular to date, or more commonly known as gastrodiplomacy (Rockower, 2012). The term refers to the method of building the reputation of a country through its national cuisine (Gastrodiplomacy, n.d.). Furthermore, Rockower (2012) stated method of gastrodiplomacy refers to the use of food and national cuisine of a country as a tool for diplomatic purposes. The goal of it was to promote the nation branding and reputation of the country in the eyes of the international public. The method itself were more commonly used in East and South East Asia, where it was used for middle-power countries to distinguish themselves from other countries, as well as to display their uniqueness. So, countries such as Taiwan will not be confused with Thailand, and South Korea with Japan (Nye, 2004).

Based on the research conducted, it became clear that there actually is a connection between gastrodiplomacy and entertainment industry, such as television programs. The study conducted by Zhang (2015) pointed out the ability of a country cultural aspect, such 
as culinary culture to played a rather significant role in shaping the branding and reputation of the country where the series originated from. Furthermore, the study was also able to points out the collaboration between television series and culinary culture in popularizing the country's national cuisine abroad. While the study conducted by Kim, Kim, Agrusa and Lee (2012) provides necessary insights regarding the use of television programs as medium to promote a country's tourism department. The use of cultural aspect presented within the selected scene of the research, Jewel in the Palace were considered to be able to raise the awareness of Korean culture in the eyes of the global community (Kim, Kim, Agrusa, and Lee, 2012).

Moreover, the research conducted by Rockower (2014) provides the researcher necessary data and insights regarding the concept of gastrodiplomacy, as well as how countries such as Taiwan, Thailand, Malaysia, and South Korea's takes on conventional concept gastrodiplomacy campaign, which was by attracting the audience to experience the cultural aspect of a country through food and national cuisines. While the research conducted by Solleh (2015) provides insights regarding the use of gastrodiplomacy to promote the nation branding and identity of a country. The study emphasized on the use of media and good relationship between stakeholders as one of the main factors to succeed the campaign (Solleh, 2015).

All the researches mentioned above gave necessary insights and data to further conduct the research. As all of the findings were supporting the argument of the current research. The novelty side of the current research would be that the current research aimed to elaborate and describe the food appearances and performances within the selected scenes, which are the Korean drama, Weightlifting Fairy: Kim Bok-Joo Episode two and Korean reality show, BTS: In the Soop Episode one as a form of cultural representation of South Korea, while simultaneously being a gastrodiplomacy attempt of the country itself to promote its nation branding in the eyes of the global community. The importance of the research would be that the current research would like to identify the performative interrelationship between culinary culture and televisions programs to promote a country's national culture abroad, where the television programs were deemed to be able to generalized the cultural side of the cultural appearances, by presenting it in a more diffuse and attractive manner.

There will be two main theories that will be used to conduct the research, which are food as nation branding, as well as diplomacy and performances theory. Both the theories will be used to describe and elaborate the use of television programs as medium to conduct a gastrodiplomacy campaign, as well as cultural representation.

\section{Food as Nation Branding}

Nation branding refers to the image and reputation of a country in the eyes of the international public (Brand Trust, n.d.). Over the years, nation branding had steadily gained popularity and prominence in many countries across the world. The use of 
resources and power became one of the key factors in promoting it (Dinnie, 2016). Kotler and Gertner (2002) mentioned that a country's image and nation branding often came from its geography, history, art, music, famous citizens, and other features of the country, including cultural features.

The process of branding itself had been defined as the process to distinguish one company produce to another company produce (Jobber and Fahy, 2003 in Dinnie, 2016). This created a sense where the country's produce became the identity of the country itself. The process itself is not just merely about promoting the produce to the world, but rather as a strategic communication plan conducted by the country to promote its national branding through the produce itself (Anholt, 2005). With that being said, it created a sense where the national branding of a country should carry the identity of the country where it was originated from, making cultural aspect of a country became a rather stronger element of nation branding.

Cultural aspect of a country, such as food and national cuisine became such a promising element to promote the nation branding of a country. Culinary culture and food became more than just a form of culture, but rather as one of the essential key elements in building, as well as promoting the nation branding of a country.

Gastrodiplomacy is not merely just about promoting local cuisine abroad, but rather as an attempt conducted by the government to raise international awareness of a country's national cuisine and cultural heritage (Rockower, 2012). Gastrodiplomacy emphasized on the use of food and national cuisine as the medium to communicate the country's cultural aspect to the global public through public diplomacy method (Rockower, 2012). To date, gastrodiplomacy became a tool for foreign policy to increase the national branding and status of a country, kit had been used by many countries as a tangible symbol that helps to create a positive image of the country. The positive image would lead to attractiveness, making gastrodiplomacy became one of the stronger methods to conduct a public diplomacy campaign (Luša \& Jakešević, 2017).

\section{Diplomacy and Performances}

Diplomacy refers to the techniques and skills deployed by someone who represent the country he or she represents (Marsden, Ibañez-Tirado, and Henig, 2016). While Hüttler (2017) defines diplomacy as performance, where the stage of the performance is the streets and palaces that centers upon the spaces of political power. With that being said, diplomacy could be considered as performances conducted by the government of a country, with the goal of influencing other countries to take certain action that would be beneficial for the country itself.

Diplomacy became far more than just an attempt to influence other countries. But rather, as a performance on its own. The use of media platforms, such as television programs were deemed to be able to superseded and prefigured the 'real' by using popular culture 
(Saunders \& Vessels, 2018). The use of media and entertainment industry were said to play a big role in succeeding the campaign. The media landscape where entertainment formats have conclusively become the key factor of the campaign's success (Turner in Volcic, Z., \& Andrejevic, 2016).

With that being said, it created a sense where the collaboration between cultural diplomacy, entertainment industry, as well as media performance created a dynamic interaction. Though, the use of media, such as television programs may seem unorthodox and even provocative (Melissen, 2008). It could still be considered as effective in delivering and promoting the soft power projection, cultural outreach, and even the nation branding of the country (Melissen, 2008). Furthermore, Saunders in Saunders and Vessels (2018) also stated that television series could act as an artefact where the series originated from, where it could be viewed as an example of reflexive branding.

\section{METHOD}

To further conduct this research, the researcher would use the qualitative research methodology with descriptive measurement, where the researcher will try to describe and elaborate the food appearances and performance within the selected case studies as a form of cultural representation of South Korea, while also simultaneously being a gastrodiplomacy to promote the national branding of the country itself.

Qualitative research refers to a type of study that emphasized on the depth of data collected for the research (Ritchie, Lewis, Nicholls, and Ormston, 2003, p.3). Meanwhile, according to Cooper and Schindler (2014, p.139) defines qualitative research as a casual research design that seeks to discover the effect of a variable or variables has on another variable. Therefore, the in depth of data that would be analyzed for this research would be the gastrodiplomacy performance happening within Korean television programs, such as drama and reality shows as a form of cultural representation that could help to promote the nation branding of the country, which was South Korea. Moreover, the research would also like to elaborate the performative interrelationship between television programs and national cuisines of a country to promote the national cuisine of a country abroad.

The research itself would only be focusing on the gastrodiplomacy performance or the food and national cuisine appearance within two selected Korean television programs, which are the Korean drama, Weightlifting Fairy: Kim Bok-Joo episode two scene 28.00 until 30.00 and Korean reality show, BTS: In the Soop episode 1 scene 40.25 until 45.00. Though, both the programs were not necessarily food-themed programs, they both still encompassed the characteristics needed for this research, which was the food appearances within the selected scenes. Moreover, the different background and delivery 
method of both the selected programs also played a role in determining the success, as well as effectiveness of the campaign.

\section{RESULT AND DISCUSSION}

Based on the diplomacy and performances analysis. The researcher found out that the collaboration between cultural diplomacy, entertainment industry, and media platforms seemed to be creating a dynamic interaction. The use of media platforms such as television programs were deemed to be able to performs the cultural aspect and artifacts of the country where the programs originated from. On top of that, it was also clear that the programs were also able to conceal the cultural side of the performance itself, while simultaneously revealing the country's identity.

The programs were able to present the cultural artifacts of the country in an attractive and diffuse manner that excites the audience, which in this case was South Korea. The country had successfully infused their cultural artifacts into their entertainment industry, using popular culture. Korean Waves or Hallyu became such a global phenomenon, from their television programs, fashion, to music industry. The use of popular culture were deemed to be able to blur the political intentions of South Korea, where it were able to blur the line between politics and the popular.

Korean television programs, such as drama and reality shows were considered to be able to present the cultural artefacts of the country, which in this case was the food and national cuisine performance within the programs. This resulting in the food performances happening within the programs could be considered as a form of cultural representation. Through the analysis, the researcher found that the following scenes of both the chosen scenes from the Korean drama, Weightlifting Fairy: Kim Bok-Joo and Korean reality show, BTS: In the Soop could be considered as a form of cultural representation of South Korea.

Table 1. Food Appearance, Location, and Political Content

\begin{tabular}{|c|c|c|c|c|}
\hline Series & Scene & Description of the Scene & Location & (Geo)Political Theme \\
\hline Korean & 28:00 & The main cast of the series, & Korean & BFN eating routine as \\
\hline Drama, & to & Kim Bok-Joo was explaining & $B B Q$ & cultural metonymy \\
\hline Weightli & $29: 30$ & the BFN eating routine and & restauran & South Korea, where the \\
\hline Fairy: & & $\begin{array}{l}\text { now the eating routine } \\
\text { could prevent the feeling of }\end{array}$ & & $\begin{array}{l}\text { eating routine was usea } \\
\text { introduce the eating }\end{array}$ \\
\hline Kim Bok- & & getting too full too quickly & & routine of the locals \\
\hline Joo & & $\begin{array}{l}\text { when eating at a } B B Q \\
\text { restaurant }\end{array}$ & & \\
\hline
\end{tabular}




\begin{tabular}{ll}
\hline Episode & The way the casts were seen \\
2 & to be enjoying the food, \\
which was by eating it & together while conversing \\
and enjoying each other \\
company, as well as how the \\
juniors on the table would \\
grill the meat, and let their \\
seniors to take the first bite, \\
then they would join them \\
to \\
30:00 \\
The appearances of food \\
South Korea, where the \\
show also highlights the \\
food appearances \\
according to the BFN eating \\
routine order, which are \\
grilled meat or gugi, \\
marinated grilled meat or \\
yangyeom gugi, Korean \\
fried rice or bokkeumbap, \\
and lastly cold noodle or \\
naengmyeon
\end{tabular}

The collective eating could furtherly be considered as a form of cultural representation, where it represents one of the core values of South Korean, which was togetherness, and politeness. The two were considered to be the identity of South Korean, where it became more than just mandatory, but rather as customary

Performativity of gastrodiplomacy through the appearance of Korean $B B Q$ or gugi-gui, the appearance of food and national cuisine happening within the scenes did not solely act for entertainment purposes only, but rather as a form of cultural representation, where the food presented could carry the cultural identity of South Korea, while simultaneously being a gastrodiplomacy campaign of the country

\begin{tabular}{|c|c|c|c|c|}
\hline Korean & $40: 25$ & One of the casts, Jeon Jung & Open & The way the younger \\
\hline Reality & to & Kook who is the youngest & nature & members of the group was \\
\hline Show, & $45: 00$ & member of BTS was seen to & villa & seen to be preparing the \\
\hline BTS: In & & be cooking the food, & Gangwon- & food could be considered \\
\hline The Soop & & jjapaguri. Then, he would & do, South & to represent one of the \\
\hline Episode & & call the rest of the members & Korea & core values of South \\
\hline 1 & & to eat together, while & & Korea, which \\
\hline & & conversing and enjoying & & politeness. On top of that, \\
\hline & & each other company & & $\begin{array}{l}\text { the way the members were } \\
\text { seen to be enjoying the } \\
\text { food collectively while }\end{array}$ \\
\hline
\end{tabular}




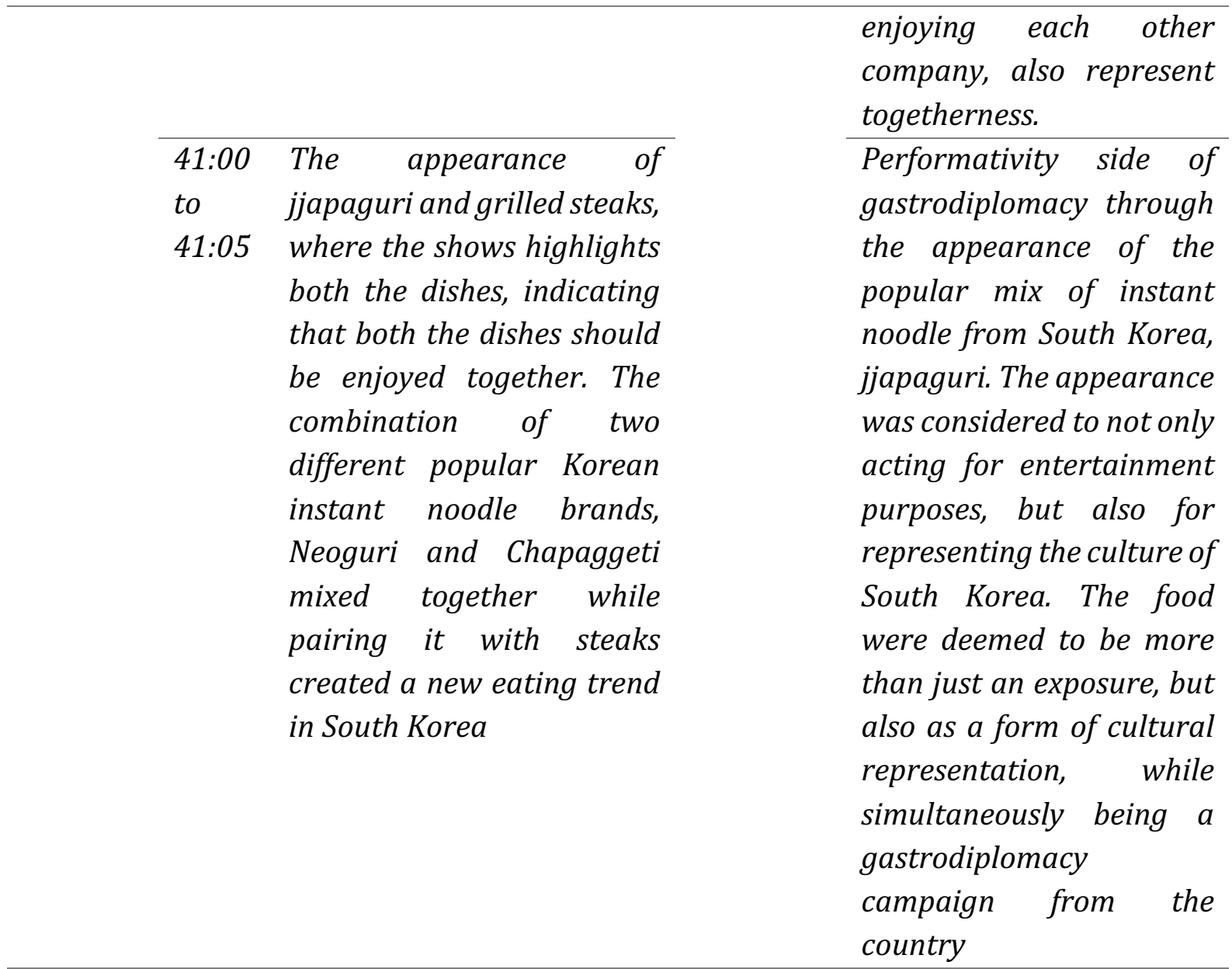

Source: Data Processed by (Researcher, 2021)

\section{Coding of the Food}

Based on the analysis, food became more than just a product, but rather as a culturallycoded product, where food was considered to be very conservative. This means, though globalization and modernization were inevitable, food remains traditional and endemic to the country where its originated from. Food culture became the medium where the past and present co-exists together, making it became the perfect object for cultural representation.

The food as nation branding theory stated the use of the country's name in food-related products could create a positive image towards the country where the food was originated from (Kotler and Gertner, 2002). In this case, the appearance of gugi-gui or Korean BBQ and jjapaguri created an imaginary benchmark for the rest of South Korean produce. The appearance had successfully created a reputation for South Korean food products as the new and upcoming eating and food trend. The reputation created a perception by the global community, where the global community appeared to think Korean cuisine as interesting, which simultaneously raising the popularity of the dishes itself. Moreover, the use of Korean language in products naming, such as gugi-gui and jjapaguri also contributes to the popularization of the Korean brand abroad. 
Furthermore, as mentioned earlier, the wording of the naming such as gugi-gui or Korean BBQ as well as jjapaguri also created a sense of ownership that carried the country's identity. This created a sense where both the dishes became the national cuisine of South Korea.

To sum up everything that has been said before, the cultural artifacts represented via food and national cuisine were able to carry the identity of South Korea, while the television programs were able to acts as the medium that not only carry the cultural message, but also concealed it. Moreover, the food and national cuisine appearances also simultaneously act as a gastrodiplomacy attempt of the country, that could help to promote the country's nation branding abroad.

\section{Engaging the Audience: Discussion of the Medium for the Performance}

Both the programs chosen for this research gained much popularity in global society. The fun and entertaining side of the programs, as well as the appearance of Hallyu actors played a big part in making the programs became such a hit, making the programs became the perfect medium to convey the message. The programs were said to be effective in delivering the campaign's message.

Both the chosen programs had successfully presented and normalized the cultural artifacts of the food appearances within the selected scenes, while simultaneously increasing the interest and curiosity from the audience. This resulting in the change of perception by the audience towards the culture presented, where it could be perceived as common, yet trendy for the audience. The use of television programs became such a strategic tool to engage the audience.

Television drama could engage the audience through the strong characterization and multi-layered story, resulting in the ability of television drama to engage its audience for a longer time. The strong storyline and characterization within the series were able to hypnotized its audience (Hill, 2019). With that being said, it created a sense where television drama was deemed to be more effective in introducing, as well as raising the awareness of the food presented within the series, where the audience would interpret the food or eating routine appearances as part of the storyline. In this case, the Korean drama, Weightlifting Fairy: Kim Bok-Joo episode two, became the perfect medium to introduce one of the national cuisines of South Korea, gugi-gui or Korean BBQ and the BFN eating routine. The fun yet entertaining background of the series had successfully hypnotized the audience to continue watching and enjoying the program.

While reality show was able to engage the audience through the relatable and real environment of the series, where the audience was able to connect with the series, as well as relate to the message delivered. The program was expected to be able to not only engage, but also create a connection between its audience. The natural and spontaneous nature of a reality show appeared to be more relatable for the audience. Hence, the instant 
connection formed (Hill, 2019). The spontaneous and relatable nature of the program created a perception of truth, where the audience were seen to believe the message delivered, resulting in the persuasive and influencing ability of the program (Hill, 2019). In this case, the Korean reality show, BTS: In the Soop were deemed to be able to influence its audience into trying the food presented, which was jjapaguri. The spontaneous comments given by the BTS members created a perception of truth, where the audience seemed to believe the message delivered done by the members, saying that jjapaguri is tasty and delicious.

Both the programs surely have their own advantages, the television drama was able to engage its audience longer, some even able to somehow hypnotize the audience. But, in the sense of persuading and influencing the audience, television drama is surely lacking. The content was deemed to be too scripted, making it hard for the audience to relate to the storyline. While reality show was considered to be more effective in doing so, the spontaneous and natural setting of reality show could influence the audience more easily and instantly. But, it could also disengage as easily (Hill, 2019). This means that though the setting of a reality show appeared to be more relatable and natural, it could also be perceived as boring and dull.

To sum up everything that being said earlier, it was clear that both the programs were able to create an engagement with their audience. Though both of the series have their own advantages and disadvantages, it was clear that both the series were effective in delivering the campaign message, where both the programs could conceal the cultural artifacts conveyed within the food appearances, while simultaneously presenting it in a more diffuse and entertaining manner. This created a sense where food could act beyond its literal meaning, which was an object for survival, but rather as a cultural coded object that carries the core identity and values of the country where it was originated from.

\section{Beyond Entertainment: Gastrodiplomacy Performance Through Television Programs}

Television programs were considered to be able to deliver the campaign message through the appearance of food and national cuisine within the series. The food was expected to be able to carry the cultural artifacts implicitly, making it became a form of gastrodiplomacy performance within the programs. The diplomacy and performance theory, as well as food as nation branding theory were able to interpret the appearances within the selected scenes as a form of gastrodiplomacy campaign conducted by the South Korean government, with the main goal is to promote the country's nation branding.

Based on the analysis conducted using both the theories, it became clear that there is connection between food and television programs, resulting in the performative interrelationship between national cuisine of a country and television programs in promoting a country's national cuisine abroad. Moreover, the food related scenes were also deemed to be capable of carrying the country's identity and uniqueness. 
The appearance of gugi-gui and jjapaguri were expected to not only raise the awareness, but also the curiosity towards the cuisine, and the culture later on. The raise of curiosity could lead to raise of interest towards the cuisine, that will be resulting in the raise of popularity of both the cuisine, and the culture. The television programs acted as the vessels or medium to deliver the campaign. This created a dynamic synergy, where the collaboration between food appearances and television programs could lead to the increase of the country's national cuisine popularity abroad.

The easy accessibility nature of television programs such as drama and reality show were expected to be more efficient in delivering the campaign's message to the global society. In gastrodiplomacy sense, the television programs were deemed to be the perfect medium to conduct the campaign. The engagement formed was one of the main factors in doing so, television drama could engage the audience for a longer time. Hence, making it the perfect medium to introduce and raise the awareness of certain national cuisine of a county. While, reality show was deemed to be able to create a perception of truth. Hence, the persuading ability of a reality show program, which makes it perfect to persuade its audience into actually trying the food presented within the series. Those characteristics differentiate television drama and reality show from the rest of other television programs, such as documentaries and cartoons.

In this case, the Korean drama, Weightlifting Fairy: Kim Bok-Joo was considered to be effective in introducing gugi-gui or Korean BBQ, as well as the BFN eating routine. The series was able to introduce the cuisine and eating routine to their audience, through the exposure. Furthermore, as mentioned earlier the television drama also had successfully concealed the cultural side of both the exposure, while presenting it as timeless and normal. Whereas the Korean reality show, BTS: In the Soop was considered to be effective in influencing the audience into trying jjapaguri. The series was deemed to be effective in increasing the interest and curiosity, which lead to the increase of the popularity itself. On top of that, the spontaneous and natural nature of the series also created a perception of truth, where the audience seemed to believe the messages delivered within the series. It was to no surprise that gugi-gui and jjapaguri would be considered as the perfect medium to represent the South Korean culture.

Hanshik globalization became the first gastrodiplomacy campaign conducted by the South Korean government, with the main goal of to introduce the Korean cuisines and planted the South Korean cultural roots worldwide (Cwiertka in Kim and Choe, 2014). The strategy behind the campaign itself was to present Korean cuisines as a timeless food, where the cuisine was unaffected by industrialization and modernization, and kept traditional and endemic to Korean culture (Cwiertka in Kim and Choe, 2014). The goal of the campaign itself was to introduce the traditionality and conservativeness of Korean cuisine, while simultaneously raising curiosity and interest of Korean cuisine in the eyes of the global society. 
It was to no secret that the Korean Wave or Hallyu had successfully gained the global interest through its entertainment industry, such as K-Pop and K-television programs. The success created an opportunity for hanshik to take part. The collaboration between the two created a synergy. It could be seen from the growing number of food-themed films and television programs in the past decades. The television programs were able to deliver the campaign message in an interactive and implicit manner that could be accessed by the global society. The easy accessibility nature of a television program enables the global society to be exposed to the various kind of a country's national cuisines within a single click. This resulting in the effectiveness of a strategic commercialized gastrodiplomacy campaign compared to a conventional or traditional gastrodiplomacy campaign. The engagement formed between the series and its audience created a connection between the two, which will be resulting in the raise of curiosity, and interest. Hence, the influencing ability of a commercialized gastrodiplomacy campaign.

\section{CONCLUSION}

The use food and national cuisine as a medium for cultural representation was deemed to be effective, as food was considered as one of the cultural artifacts of a country. This resulting in the use of food as a tool for cultural diplomacy, such as gastrodiplomacy. The use of gastrodiplomacy were considered to be effective in promoting the nation branding of a country, as it was able to not only raise the awareness of the food itself, but also curiosity towards the food. Countries across the globe, such as South Korea used and developed various gastrodiplomacy approach. One of them being by collaborating a gastrodiplomacy campaign with the use of media platforms, such as television programs.

Two television programs were chosen, the Korean drama Weightlifting Fairy: Kim BokJoo with the appearance of gugi-gui or Korean BBQ and the BFN eating routine, and Korean reality show BTS: In the Soop with the appearance of jjapaguri. Both the appearance from the two programs were considered to carry the cultural identity of South Korea, making it became a form of cultural representation, while simultaneously being a commercialized gastrodiplomacy campaign of the country. The analysis of this research was developed on three levels, which were from the food performance angle, the cultural representation angle, and gastrodiplomacy angle.

The food performance angle was able to create an imaginary benchmark for the rest of South Korean produces, where the food performances within the series were seen as fascinating and trendy, which resulting in the raise of curiosity towards the food by the global audience, while simultaneously representing the cultural artifact and identity of the country. The cultural representation angle was able to elaborate the use of television programs as the medium in which the representation is happening, the programs were 
considered to be able to conceal the cultural side of the representation while presenting it in a more diffuse and entertaining way, making it appeared as timeless yet trendy. The gastrodiplomacy angle was able to unveil the collaboration of entertainment industry, such as television programs and gastrodiplomacy campaign, where the combination created a dynamic synergy.

Furthermore, the research was able to designate the novelty side of a gastrodiplomacy campaign, where it could be furtherly conducted using entertainment industry, such as television programs. The use of television programs was considered to be more effective in delivering the campaign, making commercialized gastrodiplomacy campaign deemed to be better fitted and suited to carry a cultural diplomacy campaign. The collaboration of the two was able to engage the global audience, and even created a connection, which will lead into raise of interest and action.

\section{REFERENCES}

Anholt, S. (Eds.). (2005). Brand new justice: How branding places and products can help the developing world. Oxford, United Kingdom: Elsevier Butterworth-Heinemann.

Brand Trust. (n.d.). Nation Branding. Retrieved on October 23rd 2020 from: https://www.brand-trust.de/en/glossary/nation-branding.php

Cooper, D., \& Schindler, P. (2014). Business Research Methods. Boston, USA: McGrawHillrwin.

Dinnie, K. (2016). Nation Branding: Concepts, Issues, Practice. New York, NY: Routledge.

Gastro-diplomacy. (N.d.). Retrieved on October 12th 2020 from the World-Wide Words Website: http://www.worldwidewords.org/turnsofphrase/tp-gas1

Gray, C. S. (2011). Hard Power and Soft Power: The Utility of Military Force As An Instrument of Policy in the 21st Century. Pennsylvania, PA: Strategic studies institute.

Han, H. J., \& Lee, J. S. (2008). A study on the KBS TV drama Winter Sonata and its impact on Korea's Hallyu tourism development. Journal of Travel \& Tourism Marketing, 24(2-3), 115-126. DOI: 10.1080/10548400802092593.

Hill, A. (2019). Media Experiences: Engaging with Drama and Reality Television. London: Routledge. 
Hüttler, M. (2017) The performance of diplomacy in the early modern world. An international symposium, Don Juan Archive, Vienna, 17-18.

Kim, K., \& Choe, Y. (Eds.). (2014). The Korean Popular Culture Reader. Durham; London: Duke University Press.

Kim, S., Kim, M., Agrusa, J., \& Lee, A. (2012). Does a food-themed TV drama affect perceptions of national image and intention to visit a country? An empirical study of Korea TV drama. Journal of Travel \& Tourism Marketing, 29(4), 313-326. DOI: 10.1080/10548408.2012.674869.

Kotler, P., \& Gertner, D. (2002). Country as Brand, Product, and Beyond: A Place Marketing and Brand Management Perspective. Journal of Brand Management, 9(4/5), 249261. DOI:10.1057/palgrave.bm.2540076.

Leonard, M. (2002). Public Diplomacy - Foreign Policy Center. London, England: Foreign Policy Center.

Luša, Đ., \& Jakešević, R. (2017). The role of food in diplomacy: Communicating and "winning hearts and minds" through food. Media Studies, 8(16). DOI:10.20901/ms.8.16.7.

Marsden, M., Ibañez-Tirado, D., \&amp; Henig, D. (2016). Everyday diplomacy. The Cambridge Journal of https://doi.org/10.3167/ca.2016.340202

Anthropology,

$34(2)$.

Melissen, J. (2008). The New Public Diplomacy: Soft power in International Relations. Hampshire, UK: Palgrave M

Ministry of Culture, Sports and Tourism and Korean Culture and Information Service (n.d.). Hallyu (Korean Wave) Retrieved on October 16th 2020 from: http://www.korea.net/AboutKorea/Culture-and-the-Arts/Hallyu

Nye, J. S. (2004). Soft power: The Means to Success in World Politics. New York, NY: Public Affairs $^{\mathrm{TM}}$.

Pamment, J. (2014). New public diplomacy in the 21st century: A comparative study of policy and practice. London, England: Routledge Taylor \& Francis.

Ritchie, J., Lewis, J., Nicholls, C., \& Ormston, R. (Eds.). (2003). Qualitative Research Practice: A Guide for Social Science Students and Researchers. London, United Kingdom: SAGE Publications. 
Rockower, P. (2012). Recipes for Gastrodiplomacy. Place Branding and Public Diplomacy, 8(3). 235-246. DOI: 10.1057/pb.2012.17

Rockower, P. (2014). The state of gastrodiplomacy. Public Diplomacy Magazine, 11(14), 434-435. Retrieved on October 15th 2020 from: https://static1.squarespace.com/static/5be3439285ede1f05a46dafe/t/5be351 1daa4a996fcaa498f3/1541624135259/GastroDiplomacy

Saunders, R. A., \& Vessels, J. (2018). Televisual diplomacy: I am the ambassador and Danish NATION branding at home and abroad. Politics, 39(4), 430-447. https://doi.org/10.1177/0263395718805403

Scharf, S. (2016). The Campaign to Make You Eat Kimchi. Retrieved on October 14th 2020 from: https://priceonomics.com/the-campaign-to-make-you-eat-kimchi/

Solleh, F. M, (2015) Gastrodiplomacy as a Soft Power Tool to Enhance Nation Brand. Journal of Media and Information Warfare, 7.161-199. ISSN: 1985563X.

Volcic, Z., \& Andrejevic, M. (2016). Commercial Nationalism Selling the Nation and Nationalizing the Sell. Hampshire, UK: Palgrave Macmillan.

Zhang, J. (2015). The food of the worlds: mapping and comparing contemporary gastrodiplomacy campaigns. International Journal of Communication, 9, 24. DOI: 1932-8036/20150005. 